\title{
Using of an Auxetic Structure as Reinforcement of a Bending Reinforced Concrete Beam
}

\author{
Tarkk Baran \\ Department of Civil Engineering, Osmaniye Korkut Ata University, Osmaniye 80000, Turkey
}

\begin{abstract}
Materials which have negative Poisson's ratio are entitled as auxetics. Auxetics can be designed as micro- to macro-sized structures. The use of auxetics in civil engineering structures has been studied only to a limited extent. In this study, a re-entrant medium-size auxetic structure is employed as reinforcement of a reinforced concrete beam. The beam is subjected to static and dynamic loading conditions and then investigated by means of maximum vertical displacements of the beam. Besides, normal stresses and shear stresses of the concrete are also assessed. To interpret the performance of the auxetic reinforcement, obtained results are compared with the results of another beam which has non-auxetic reinforcement. The results show that these structures behave with bending compatibility as expected and due to the negative Poisson's ratio, they led to shear strength increase. Auxetic structures can be employed as reinforcement in a beam. Besides, they can be employed without concrete to increase the shear strength in the case of high shear and impact strength if it is needed.
\end{abstract}

Key words: Auxetic, re-entrant cell structure, negative Poisson's ratio, auxetic reinforcement, indentation resistance.

\section{Introduction}

In classical engineering materials applications, if the object is under the effect of the tension in the axial direction, it becomes longer and in the transverse directions, the cross-section becomes thinner. This fundamental mechanical property of the material is known as Poisson's ratio (v). For an isotropic material if the axial axis is assumed as $x$, Poisson's ratio is defined by Eq. (1).

$$
v=-\frac{\varepsilon_{y}}{\varepsilon_{x}}
$$

where $\varepsilon_{x}$ is tensile strain in the axial direction and $\varepsilon_{y}$ the transverse strain. By the definition, it is always positive and gets values $0 \sim 0.5$. On the contrary if an auxetic material or structure subjected tension in the longitudinal direction the cross-section becomes thicker or object subjected pressure in the longitudinal direction the cross-section becomes thinner. Thus, Poisson's ratio gets negative values and this property

Corresponding author: Tark Baran, assistant professor, research fields: composite structures, advanced materials, structural engineering and computational mechanics. is named as auxetic behaviour and introduced for a synthetic foam by Lakes [1].

There are many types of structures defined as auxetic. These structures can be classified by cell size micro-scale (nm to $\mu \mathrm{m})$, meso-scale ( $\mu \mathrm{m}$ to $\mathrm{cm}$ ) and macro-scale ( $\mathrm{cm}$ to $\mathrm{m}$ ) by their structure size. Most of researchers have been researching mesoscale structures. Basically, there is a cell which shows auxetic behaviour in the structure and this form repeats all over the structure body (see Fig. 1) [2-7]. Lim [3] gives another classification by cell structure such 2D and 3D re-entrant structures, chiral structures, rotating rigid units, angle-ply laminates, molecular auxetics, microporous and liquid crystalline and polymer models. Liu and $\mathrm{Hu}$ [8], Yang et al. [4] also used same classification. Smith et al. [9] and Gasper et al. [10] developed new type of auxetic structures.

Developing a new auxetic cellular structure has not been achieved until Cabras and Brun [11, 12]. They showed a systematic analysis of the mechanism of auxetic behaviour. This method emerges that nearly all auxetic structures are known from the literature. Unfortunately, while this method can be successful for 


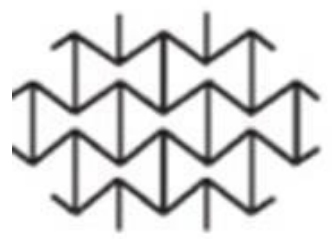

a

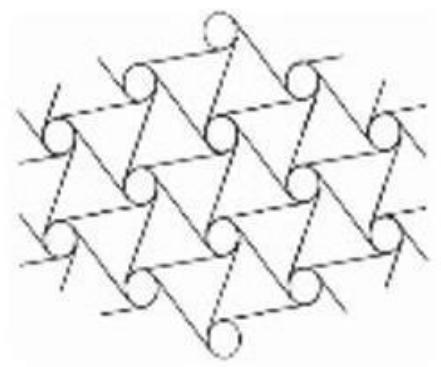

b

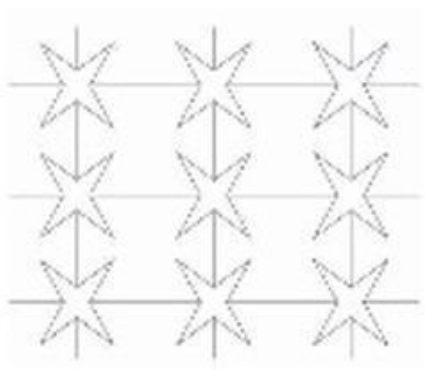

C

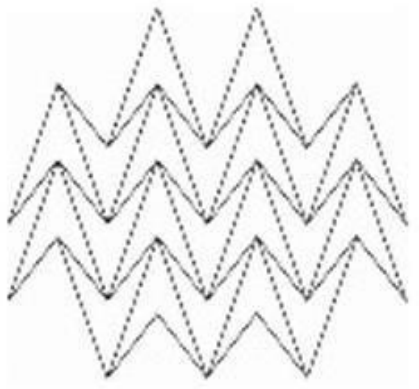

d

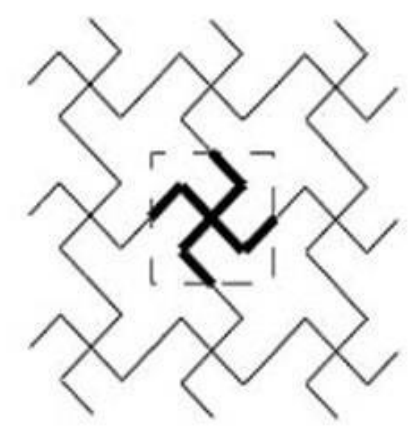

e

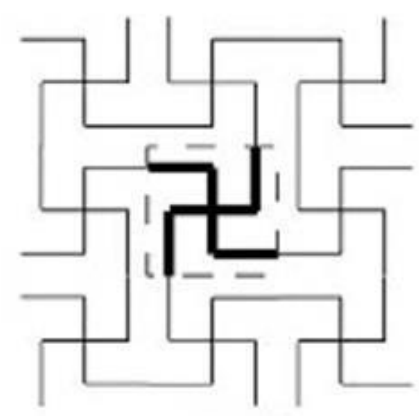

f

Fig. 1 Auxetic structures: (a) re-entrant hexagon, (b) chiral honeycomb, (c) starshaped honeycomb topology, (d) double arrow head honeycomb topology, and (e \& f) missing rib or lozenge grid.

2D structures, in 3D it is not very accurate because identification can be very complex and auxetic behaviour appears in 2D planes.

Auxetic materials can be found in the nature and can be produced with use of the non-auxetic main material of the fibres [13-16]. For example, polymeric auxetic materials have been produced in the form of foam, fibers and composites. Auxetic microporous polymers is a $2 \mathrm{D}$ model of connected network of nodules and fibrils. Because of interconnection of nodules by fibrils, the microporous polymeric foam has got highly auxetic behaviour. Thanks to this observation auxetic structures can reproduce by hinging nodules [17].

An auxetic fibre was produced by Alderson et al. [18]. They used a thermal processing technique for forming auxetic polypropylene (PP). The necessity of the technique for auxetic fiber production is maintaining the minimum draw ratio. For the fabricating polypropylene fiber, the fiber should be flexible enough to show ability to achieve auxetic behaviour [19]. Thus, for producing the auxetic foam Lakes [1] used copper.

Negative Poisson's ratio (NPR) has got a significant role for the definition of the mechanical properties of the auxetic structure. In the mechanics of materials, mechanical properties of materials can be converted each other by use of Poisson's ratio by the following equations:

$$
\begin{array}{r}
G=\frac{E}{2(1+v)} \\
K=\frac{E}{3(1-2 v)}
\end{array}
$$

where, $G$, the shear modulus, $E$, the Young's modulus or the elastic modulus, $K$, the bulk modulus and $v$ is the Poisson's ratio. Most of structural materials are required to have higher $G$ and $K$. If somehow $E$ remains constant and Poisson's ratio changes, $G$ and $K$ 
can be tuned to compensate the needs for the application. Since the NPR material has very high $G$ and low $K$, therefore it is hard to shear the material but easy to deform volumetrically [4]. According to Janus-Michalska [20], materials with NPR are more elastic and they can easily turn back unloaded form than non-auxetics. However, their highly elastic behaviour, auxetics possesses limited stiffness than material which they made from because their structure needs more voids to allow deformation of ribs and nodules [4]. Owing to material flows into the vicinity of the load, stiffness can be increased. This property creates dense area on the impact zone therefore auxetic hinged structures have got high indentation resistance [7].

Under plane bending of an auxetic plate it displays synclastic or double curvature. This behaviour is not like the anticlastic curvature of plates made from conventional materials [21]. Synclastic bending of the plate exhibits no damage due to the crimps induced by in-plane buckling. A plate made from conventional material produces a saddle-shaped surface but with use of auxetic material the plate can easily be deformed as dome-shape or double-curved shape [21]. One of the advantages of auxetic structures is high damping capacity. The energy dissipation levels of an auxetic structure may be fifteen times higher than conventional foams and five to six times higher than high density conventional foams. They have also high acoustic absorption levels $[9,16]$. Thanks to the pores of the auxetic structures, the material exhibits a variable permeability under pressure and tension. This property can be used for developing smart filter applications and in the field of medical applications $[6$, 7, 21, 22].

Auxetic structures and materials have improved properties due to negative Poisson's ratio e.g. advanced plain strain fracture resistance, advanced shear modulus, acoustic response, shock absorbing capacity etc. There are many types of auxetic structure in the literature. Their application areas are very wide
[3]. From the first introduction date, auxetic materials are interest of many engineering applications. Impact resistant laminates [8, 23], microwave absorbers [24] and medical prosthesis applications [22] are important examples at first glance. Viscoelastic damping properties of auxetic materialsare are examined by Chen and Lakes [25]. The cyclic stress-strain behavior of auxetic materials is important in terms of damping, especially since the material has high vibration absorbing properties. In polymeric foam core sandwich constructions, viscoelastic behavior of the foam is expected to play a significant role in the absorption and dissipation of energy, especially during dynamic loading [16, 26, 27]. Vibrating transmission and damping capacity under dynamic loading are important considerations in selecting foam materials for applications where both vibro-acoustic and structural integrity targets need to be met. Combined experimental results on negative Poisson's ratio open celled foams from both a vibration and cyclic fatigue point of view are presented by Scarpa et al. [26]. Under repeated compressive forces, the material has got many advantages in terms of indentation resistance over $100-150 \mathrm{~Hz}$, stability of stiffness under cyclic loading, and damping capacity for energy absorption [18]. The application showing direct auxetic effect is that the auxetic structure is used as a fastener [13]. To remove auxetic fiber samples, three times more energy is required than equivalent positive Poisson's ratio fibers, the NPR sample withstood two times more load. Similar behaviour can also be applied to biomedical intercostal muscle anchors [22]. Different forms of auxetic structures are used in textile industry in two different ways; using auxetic fibres to produce auxetic textile or using conventional fibres to produce textile in auxetic structure pattern [21, 28]. Because of their capacity to resist shocks and to absorb vibrations, auxetic structures can be applicable in aerospace and automotive industry. An auxetic chiral geometry airfoil with morphing characteristic can be used for improving flow conditions, 
minimizing drag and improving control of aircraft. Besides this, there is no need to flap mechanism [14]. Auxetic structures have high shear modulus and strength, high toughness and great bending compatibility thus they are particularly suitable for sandwich construction applications [29, 30]. Besides aforementioned applications, auxetic structures can be used in area of biomedical, sport and protection [31-33]. Some type of compressed fibre mats also can exhibit auxetic behaviour. Behaviour of these types of fibre structures were also examined and their mechanic models were developed [34, 35].

In this paper, a concrete beam's behaviour is investigated in which it is reinforced with planar re-entrant structure. There is a lack of research in the literature about the application of auxetic structures in civil engineering structures. There is a very high positive potential of this material in civil engineering applications, especially if considering auxetic's high shear resistance, synclastic curvature behaviour, bending compatibility, vibration damping capacity and high indentation resistance. The author thinks that using auxetic structures in vertical frame and shear wall elements will contribute to lateral behaviour and resistance of civil engineering structures. In addition, it is predicted that the confinement effect which increases the concrete strength, will increase due to auxetic behaviour. In this sense, re-entrant structure with steel material properties was used in the study, considering production, material selection and applicability.

\section{Analysis}

If a cell considered honeycomb structure in which all elements have positive Poisson's ratio, deformed by rib hinging, the structure will have a new form called re-entrant honeycomb (Fig. 2). The alignment of the diagonal ribs along the horizontal direction when stretched, causes them to move apart along the vertical direction. This structure is the most familiar auxetic structure and has negative Poisson's ratio.
Unit honeycomb cells have isotropic properties. But if the cell geometric layout different from regular one cell behaviour shows anisotropic properties. A honeycomb unit cell is defined by cells wall length $(l$ and $h$ ), wall thickness $(t)$ and internal cell angle $(\theta)$. According to Scarpa et al. [36], Gibson and Ashby defined $v$ in-planeas following form:

$$
v_{12}=\frac{\cos ^{2} \theta}{(\alpha+\sin \theta) \sin \theta} \frac{1-\beta^{2}}{1+\beta^{2} \cot ^{2} \theta}
$$

$\theta$ is effective for negative $v$ as seen from Eq. (5) so for the auxetic behaviour $\theta$ must satisfy the following criteria:

$$
\theta_{\text {min }}=\sin ^{-1}\left(-\frac{\alpha}{2}\right)
$$

In plane mechanical properties of auxetic honeycombs significantly depended on geometric properties of the unit cell [36]. It can be realized that, deformation mechanism of an auxetic structure was obviously different from the mechanism of a conventional honeycomb cell structure. A honeycomb structure has positive Poisson's ratio, vertical axis cells close towards the horizontal axis while stretching the network in the vertical direction. Thus, a positive Poisson's ratio occurs in the structure. On the contrarily, in an auxetic behaviour, while cell stretching vertical direction, vertical axis cells become distant from the horizontal axis. It is observed that the main stresses occur in ribs while joints are unstressed [37].

After the hinging of the ribs cell form is shown in Fig. 3. If a single cell is considered and analysed, Poisson's ratio and Young's modulus in the direction of loading are given by Smith et al. [36].

$$
\begin{gathered}
v_{x y}=\frac{\sin \theta(h / l+\sin \theta)}{\cos ^{2} \theta} \\
E_{x}=k \frac{(h / l)+\sin \theta}{b \cos ^{3} \theta}
\end{gathered}
$$

and the $k$ parameter is

$$
k=E_{s} b\left(\frac{t}{l}\right)^{3}
$$

where the $h$ is the half length of the horizontal rib, $l$ is 


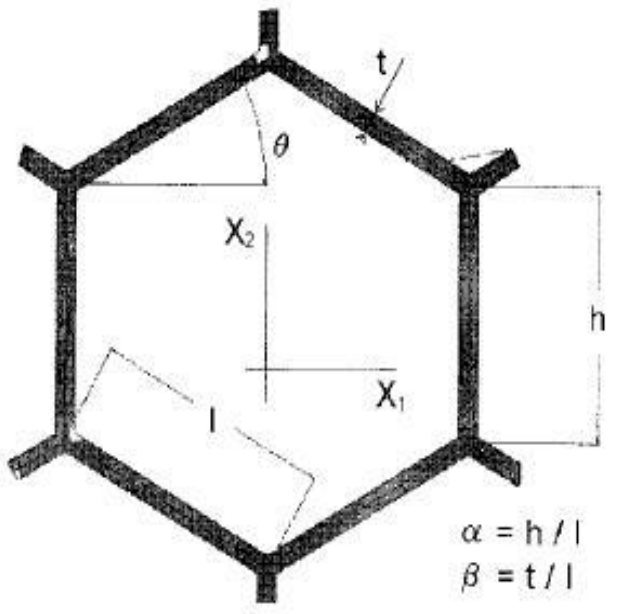

(a)

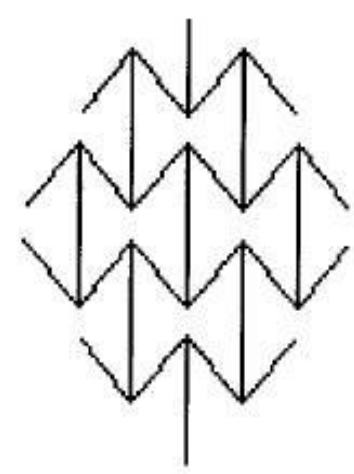

(b)

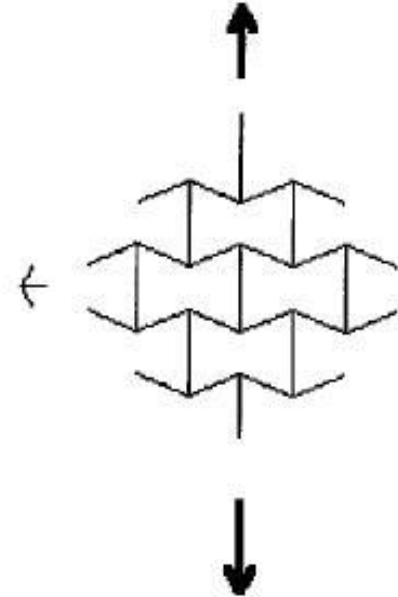

(c)

Fig. 2 Unit cells: (a) non-auxetic cell; (b) Re-entrant (hinged honeycomb) cell; and (c) Auxetic behavior.

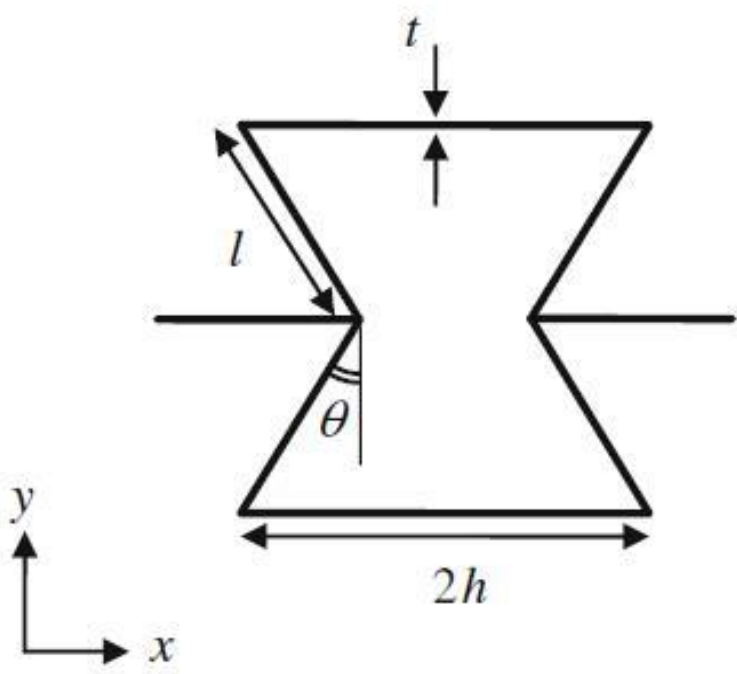

Fig. 3 Re-entrant cell.

the length of the inclined rib, and $t$ is the thickness of the rib, $b$ is the depth of the cell and $E_{s}$ is the Young modulus of the cell wall material.

In the study, a simple supported reinforced concrete (RC) beam with a length of $5,000 \mathrm{~mm}$ and a square-shaped cross-section is modelled using finite element method [38]. One side length of the cross-section is modelled as $626 \mathrm{~mm}$. Auxetic and non-auxetic cells are used as RC beam reinforcement bars. Auxetic reinforcement is modelled on the transverse direction of the beam axis. All reinforcement elements are modelled as linear isotropic frame element and the concrete elements are modelled as linear elastic solid elements. In both models, the reinforcement ratio has been tried to keep as close as possible. Same patterns are used for all faces of the beam (see Figs. 4 and 5).

Steel material is used to model auxetic and non-auxetic reinforcement bars of which Young Modulus (E) is $200 \mathrm{GPa}$. In both model steel ribs are used. Each rib's thickness is modelled as $8 \mathrm{~mm}$. In auxetic cell model, $l$ length of the cell is taken as 125 
$\mathrm{mm}$ and the $h$ parameter is used as $250 \mathrm{~mm}$. $\theta$ is calculated as $-30^{\circ}$. The concrete material's Young Modulus (E) is taken as $24,855 \mathrm{MPa}$.

Firstly, the models were analysed without concrete to show auxetic behaviour. Then the models were loaded statically with uniform area loads until reaching the steel yield strength. Finally, an impact load is applied to the beam to examine the dynamic behaviour and the damping of the beam.

\section{Results and Discussions}

After axial pressure loading, both model's results can be seen from Figs. 5 to 8. As seen from the figure auxetic behaviour clearly appears. Calculated Poisson's ratio by use of Eq. (6) for one cell is -0.33 . Auxetic beam reinforcement dimensionless transverse displacement and longitudinal displacement ratio is calculated as -0.578 and for one cell same ratio is calculated as -0.871 .

Concrete material is modelled with use of solid elements. To take an account of the low shear strength of the concrete, the material is accepted as anisotropic. And Shear Modulus $(G)$ of the concrete is taken as $0.3 E$ in all directions. Both models are loaded with the same load from the nodes of the upper surface. This loading is applied to the model from 446 points of the auxetic beam and 130 points of the non-auxetic beam. The loading value is chosen to exceed the yield stress of the steel reinforcement of the beam at any point.
Maximum stress values of steel members and maximum displacement of the beam at mid span are given in Table 1.

As it can be seen from Table 1, auxetic reinforced and normal reinforced models perform almost the same vertical displacement. The normal stress on the auxetic equipped model is less than that of the conventional reinforced model. This suggests that auxetic reinforcement is less effective in normal tensile loading. However, auxetic reinforcement bears more shear stress that proofs the high shear strength of the auxetics. This is an important reinforcement behaviour for concrete which has a very low shear strength. Auxetic reinforcement can be more convenient on the side faces of beams.

Although not very high due to the stiffness of the concrete, the auxetic behaviour is seen in following figures (see from Figs. 9a to 11b). This behaviour causes an extension in the transverse direction while forming axial elongation on the lower face of the beam. The upper face reveals narrowing in the transverse direction when shortening occurs in the axial direction. Behaviour is most clearly observed in the midplane of the beam for this case.

As seen from Figs. 12a and 12b the normal stresses in the concrete are almost the same values in both beams. In the auxetic reinforced beam, a slight variation in the stress distribution is observed with the effect of the reinforcement at the edge regions.

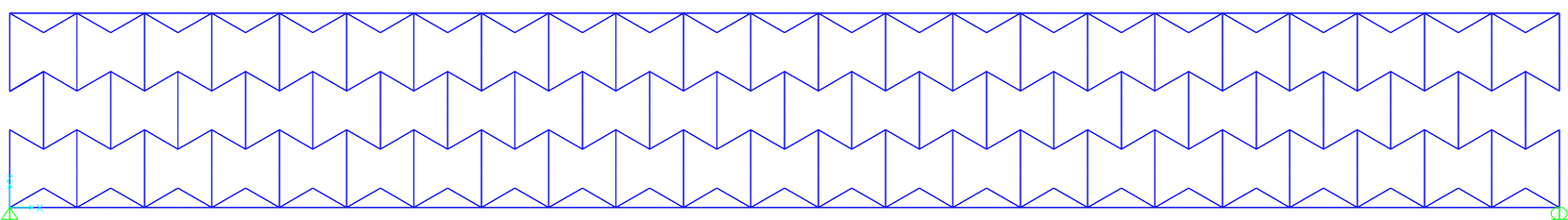

Fig. 4 Side view of auxetic reinforcement layout.

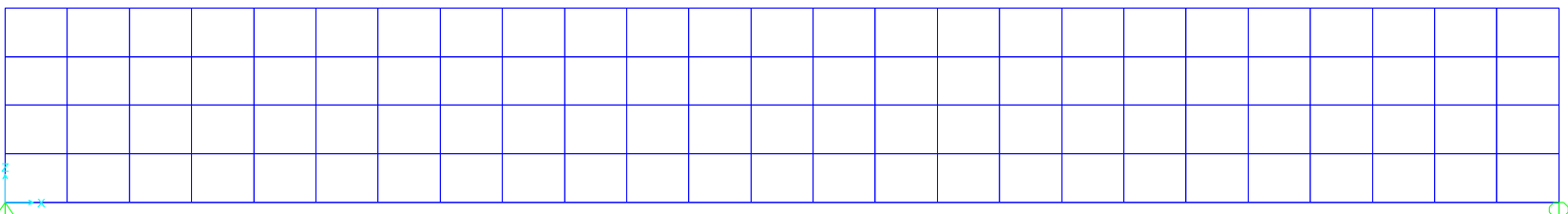

Fig. 5 Side view of non-auxetic reinforcement layout. 


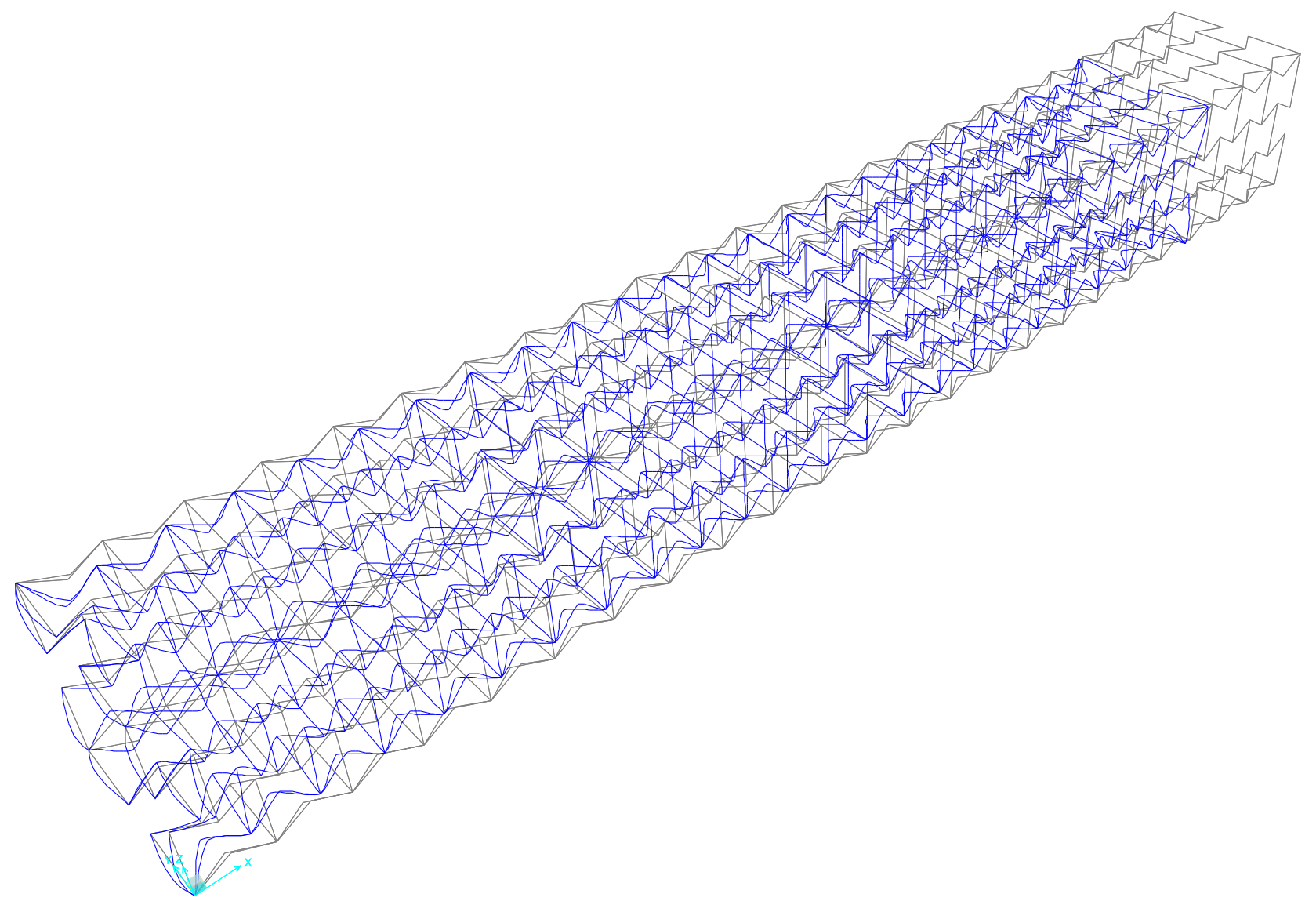

Fig. 6 3D view of deformed and undeformed auxetic reinforcement after axial compression.
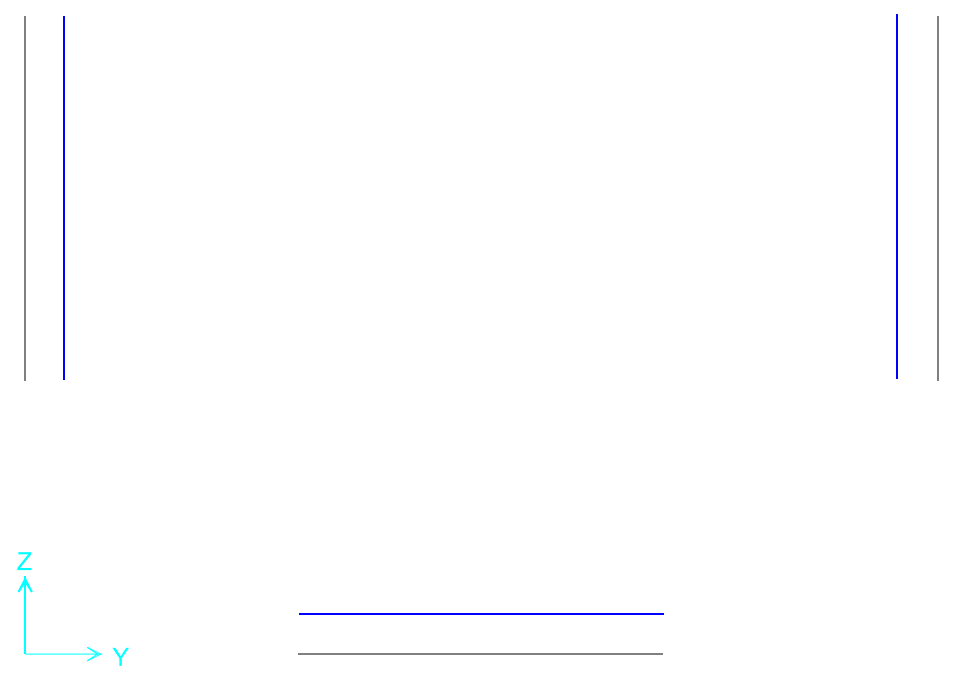

Fig. 7 2D view of deformed and undeformed auxetic reinforcement at the mid-span of the beam. 


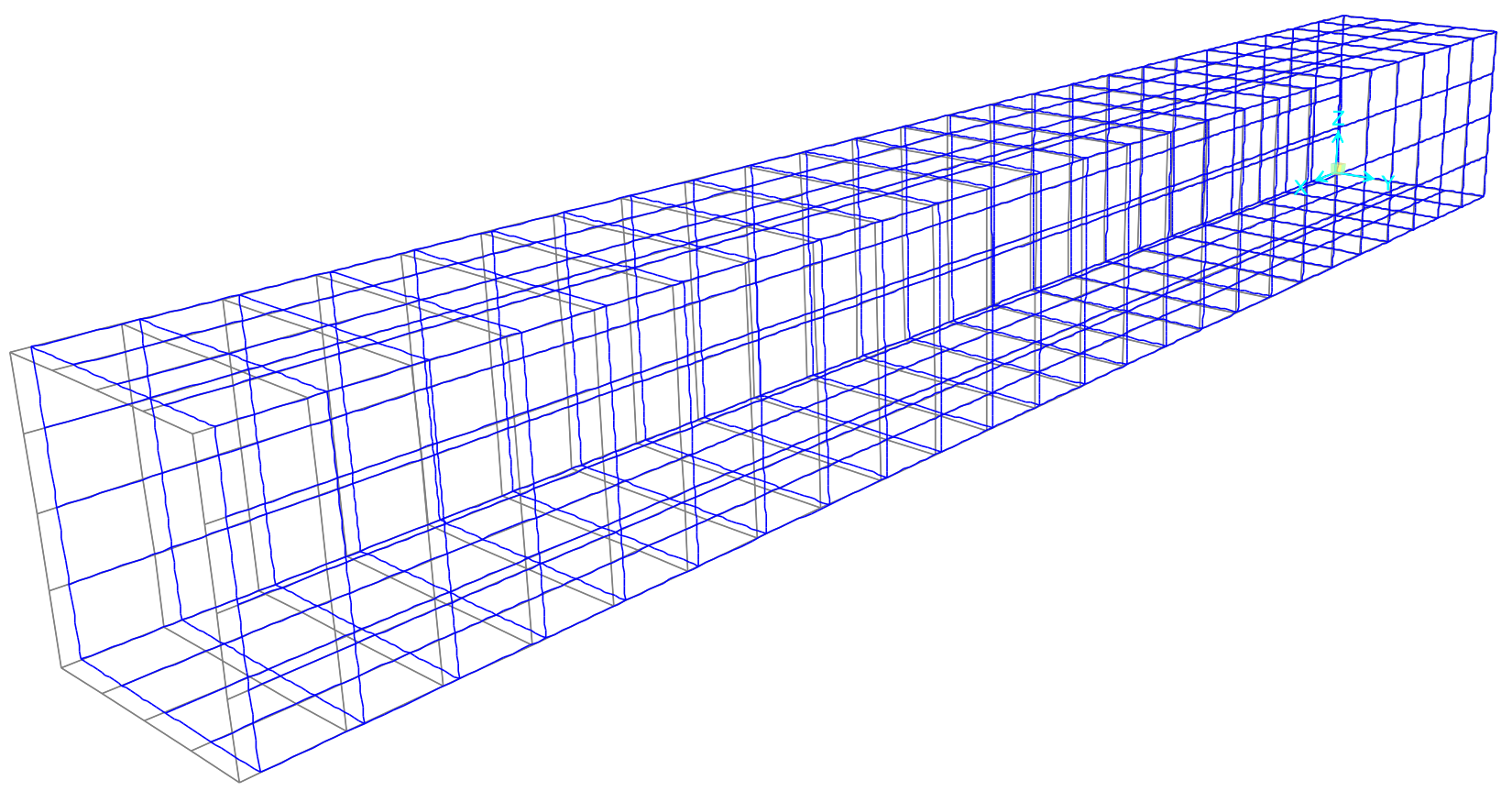

Fig. 8 3D view of deformed and undeformed non-auxetic reinforcement after axial pressure.

Table 1 Reinforcement max stresses and displacements of models.

\begin{tabular}{lll}
\hline & Auxetic reinforcement & Non-auxetic reinforcement \\
\hline $\begin{array}{l}\text { Max displacement (mm) } \\
\text { (vertical) }\end{array}$ & 22.988 & 22.510 \\
$\begin{array}{l}\text { Max normal stress (MPa) } \\
\text { (longitudinal-@ mid span)) }\end{array}$ & 403.832 & 517.093 \\
$\begin{array}{l}\text { Max normal stress (MPa) } \\
\text { (transverse-@mid-span) }\end{array}$ & 97.422 & 75.79 \\
\hline
\end{tabular}

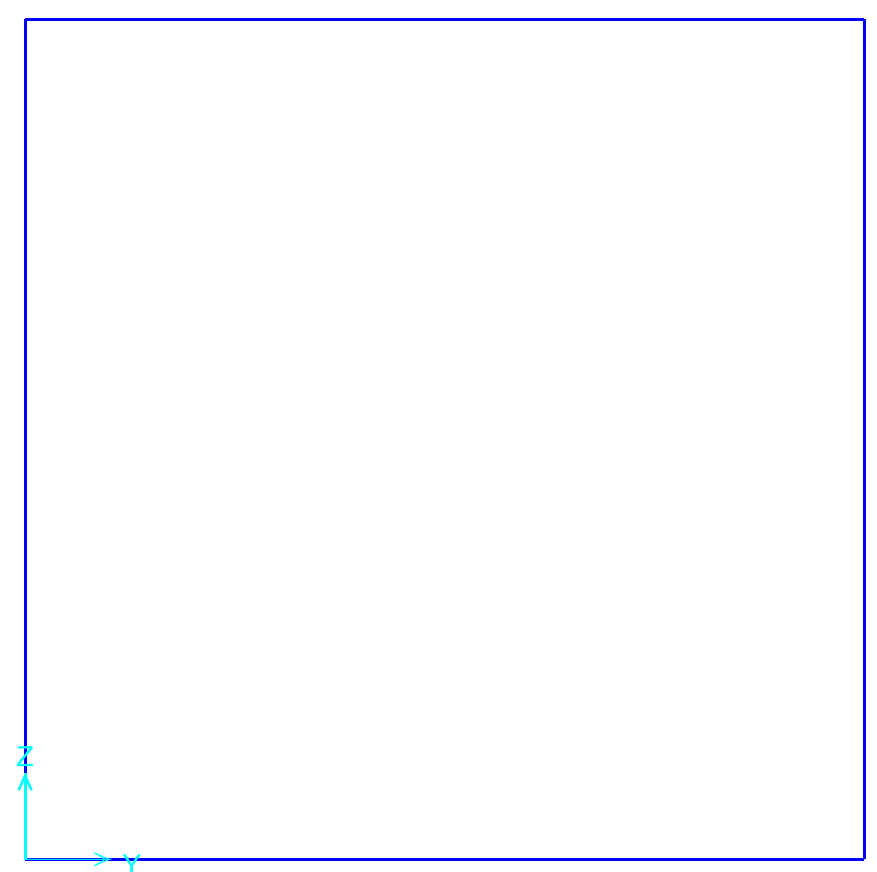

Fig. 9 2D view of deformed and undeformed non-auxetic reinforcement at the mid-span of the beam. 


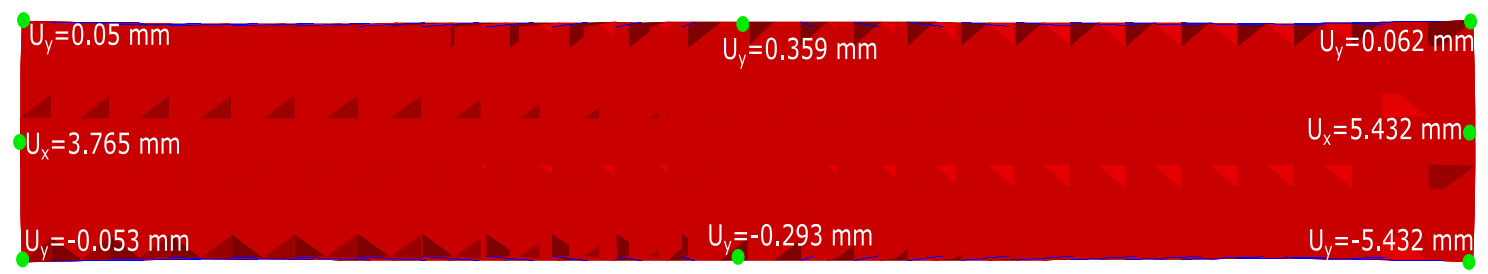

(a)

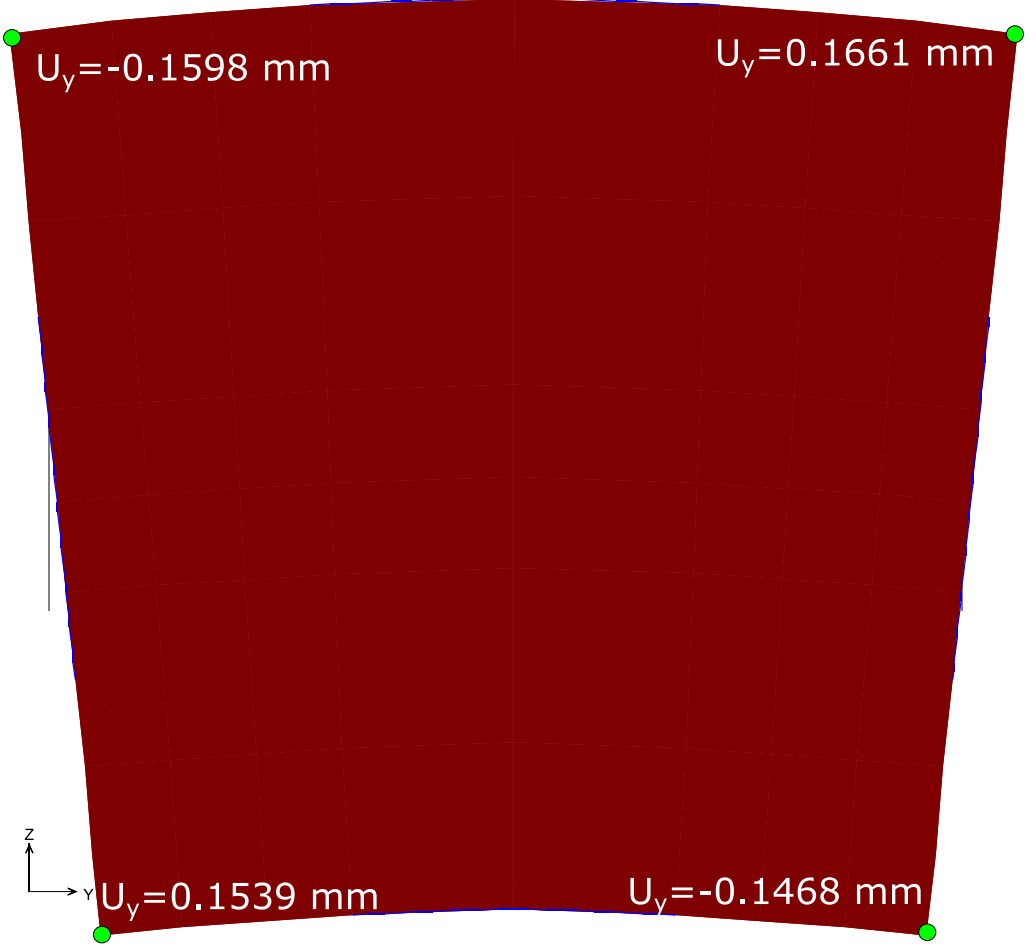

(b)

Fig. 10 (a) Plan view of auxetic reinforced beam deformation at mid-plane, (b) Elevation view of deformed shape of auxetic reinforced beam. 


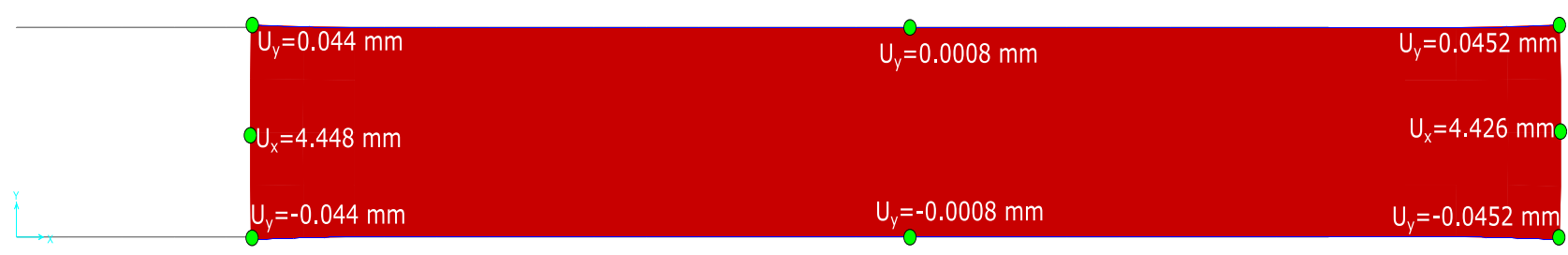

(a)

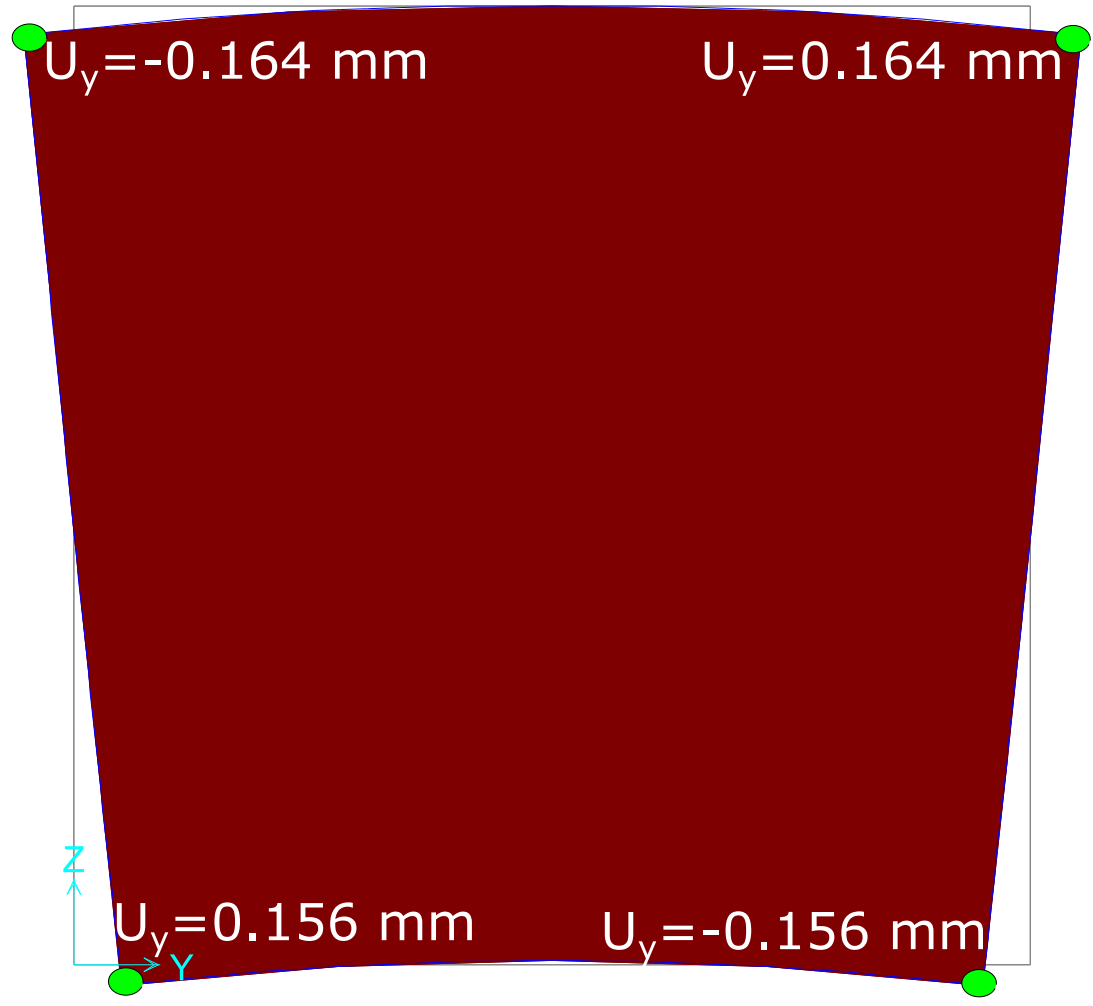

(b)

Fig. 11 (a) Plan view of non-auxetic reinforced beam deformation at mid-plane, (b) Elevation view of deformed shape of non-auxetic reinforced beam. 

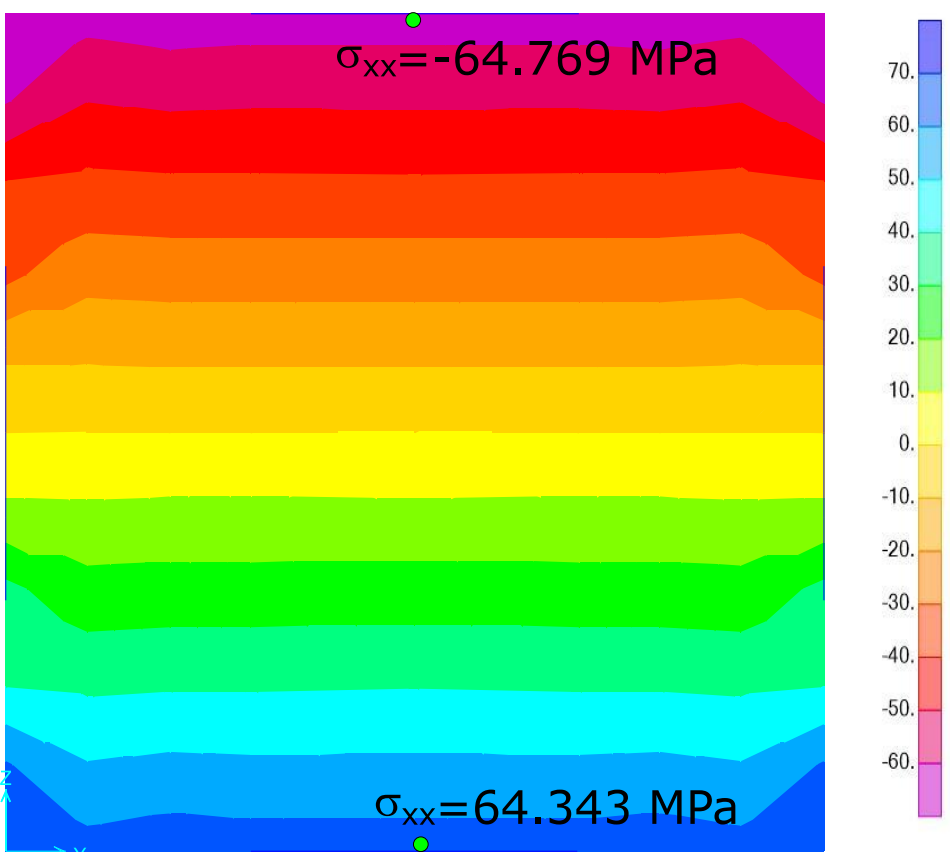

(a)
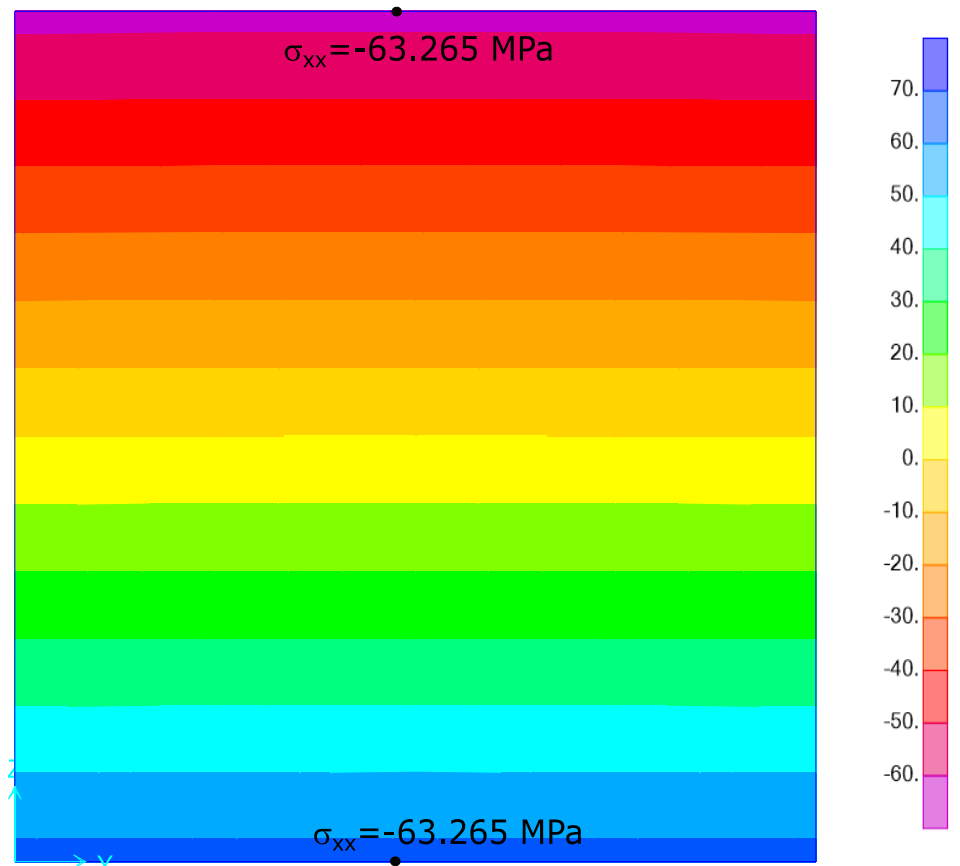

(b)

Fig. 12 (a) Elevation view of $\sigma_{\mathrm{xx}}$ stresses of auxetic reinforced beam at mid-length (concrete stresses), (b) Elevation view of $\sigma_{\mathrm{xx}}$ stresses of non-auxetic reinforced beam at mid-length (concrete stresses).

When Figs. 13a and $13 \mathrm{~b}$ are examined, it is seen that the most obvious difference in the behaviour of two different reinforcements is in shear stress distribution. The shear stresses occurring in the concrete are affected by the auxetic reinforcement and are observed very low at the near mid-length of the beam. Auxetic reinforcement has more effect on shear forces in the mid region; it causes the concrete to be exposed to less shear stress at the beam mid-region. The reason for this observation is that the auxetic 
behaviour is more effective in the middle region due to the distance of the support conditions. Auxetic reinforcement transfers the shear effects to the supports from the shortest path.

In the above literature, it is mentioned that the auxetic structure has high indentation resistance and damping effect. To investigate this effect, the beam is dynamically loaded with an impact load from the middle region and the results are given as vertical displacement time histories of a point at the mid-length. Besides shear stress time histories and normal stress time histories are also given for an element which extracted from the mid-length of the beam. Shear stress diagrams at the mid-plane of the beam showing the maximum effect of the auxetic reinforcement are also given as envelope results of the time-history analysis.

Figs. $14 \mathrm{a}$ and $14 \mathrm{~b}$ show the shear stresses of the concrete at the middle plane. As seen from the figures, the auxetic reinforcement distributes the shear

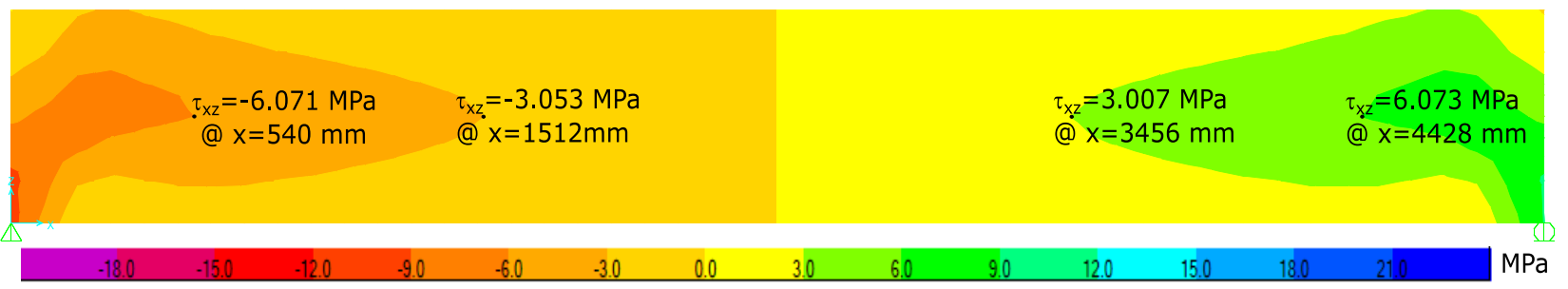

(a)

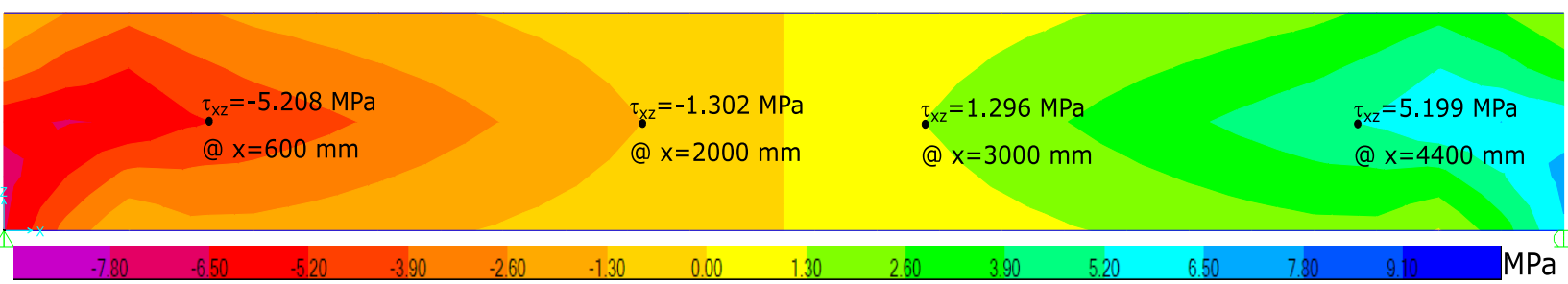

(b)

Fig. 13 (a) Elevation view of $\tau_{\mathrm{xz}}$ stresses of auxetic reinforced beam at mid-plane (concrete stresses), (b) Elevation view of $\tau_{\mathrm{xz}}$ stresses of non-auxetic reinforced beam at mid-plane (concrete stresses).

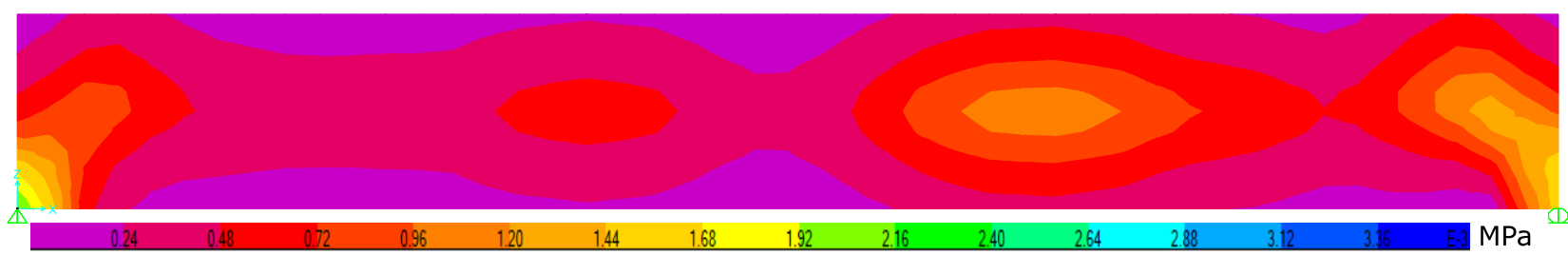

(a)

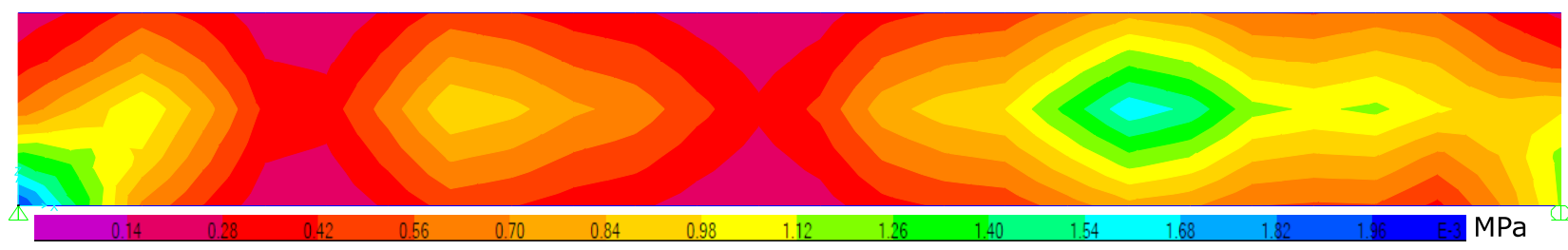

(b)

Fig. 14 (a) Elevation view of $\tau_{\mathrm{xz}}$ stresses of auxetic reinforced beam at mid-plane subjected to dynamic loading (concrete stresses), (b) Elevation view of $\tau_{x z}$ stresses of non-auxetic reinforced beam at mid-plane subjected to dynamic loading (concrete stresses). 


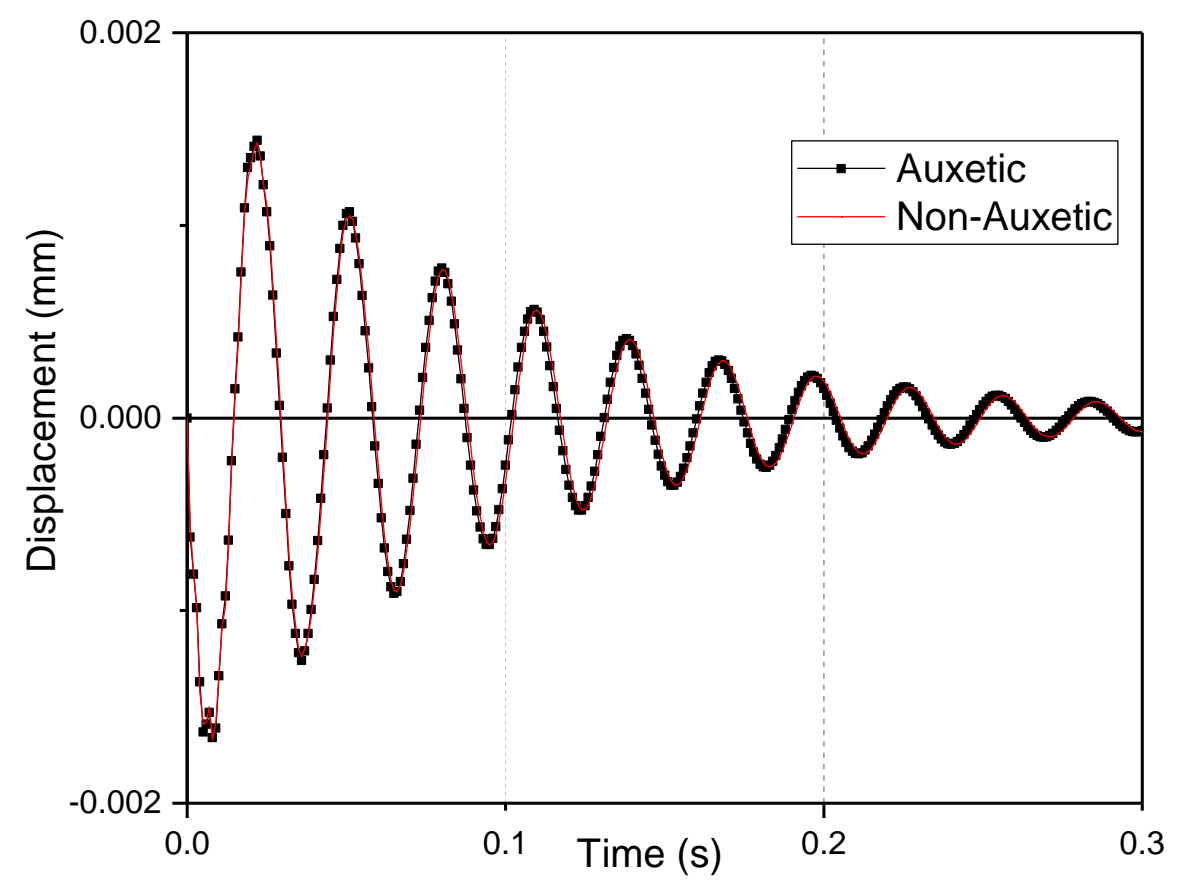

Fig. 15 Vertical displacements of the mid-length node in $\mathbf{m m}$.

stresses in the concrete without concentrating them in any region. But non-auxetic reinforcement causes intensive shear stress concentration at the beam body.

Following figures present the time history analysis result of the impact loading. Fig. 15 shows vertical displacement history of a node at the mid-section of the beam and it does not depend on the type of the reinforcement very much.

In the following figure, normal and shear stress histories can be seen for a concrete element taken from the loading zone. As seen from Figs. 16a and $16 \mathrm{~b}$, the auxetic reinforced beam shear stresses are very small compared to non-auxetic one. On the other hand, normal stresses which are obtained from auxetic reinforced beam are twice that the obtained from the non-auxetic reinforced beam. These results show, the auxetic reinforcement bears shear stresses more than the conventional one.

\section{Conclusion}

In this paper, an auxetic structure is used as the reinforcement of a bending beam. And this beam is examined and then compared with non-auxetic reinforced one. At first glance auxetic reinforcement is highly effective in concrete stress distribution. But because of the high rigidity of the concrete auxetic reinforcement does not behave as independent and effects concrete as fully auxetic. But the auxetic structure contributes to the shear strength and indentation resistance of the beam positively. In addition, there is a possibility that auxetic behaviour may increase the "confinement effect" in the subjected compression elements. The damping behaviour is not investigated due to the constant damping ratios used in dynamic equations. This paper demonstrates that the use of auxetic structures with another material with high rigidity will not be a very high effect, but that auxetic structures can be used alone or with concrete in applications where high shear strength is required. With use of different cell types, materials and sizes, auxetic structures can be put into practice in civil engineering structures.

\section{Data Availability}

Data sharing is not applicable to this article. This article contains all the data generated or published 


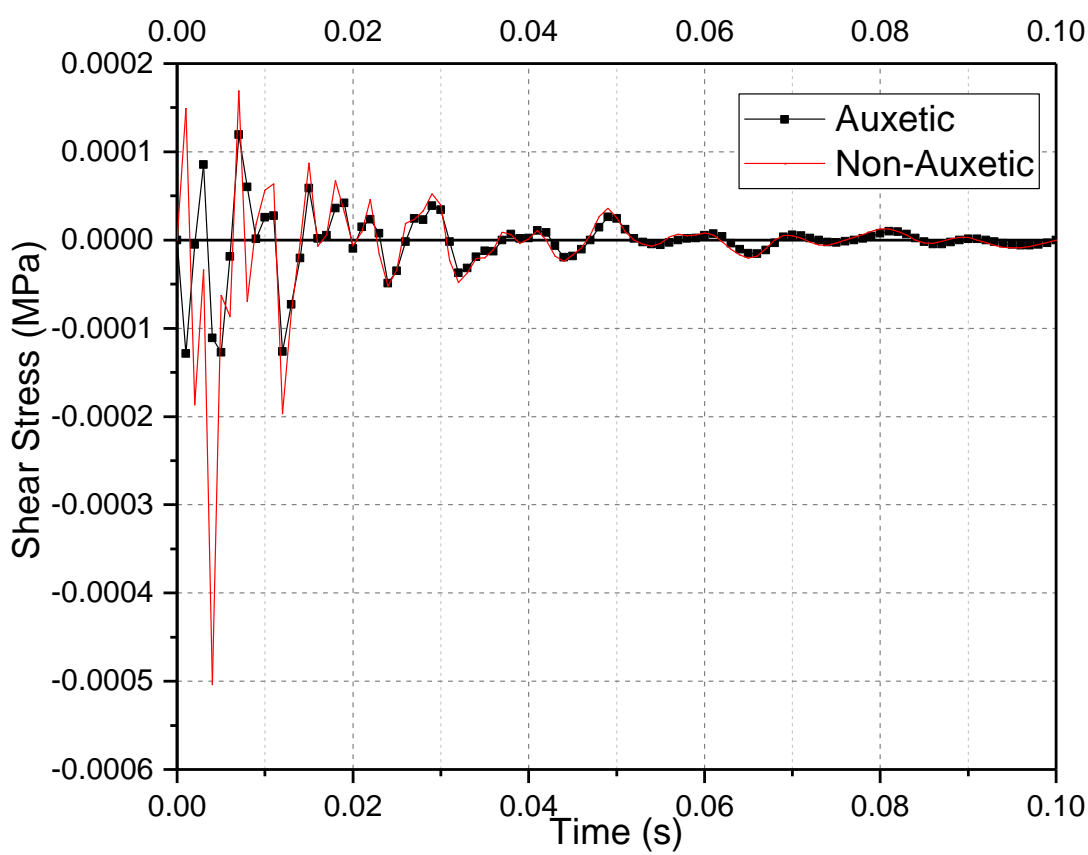

(a)

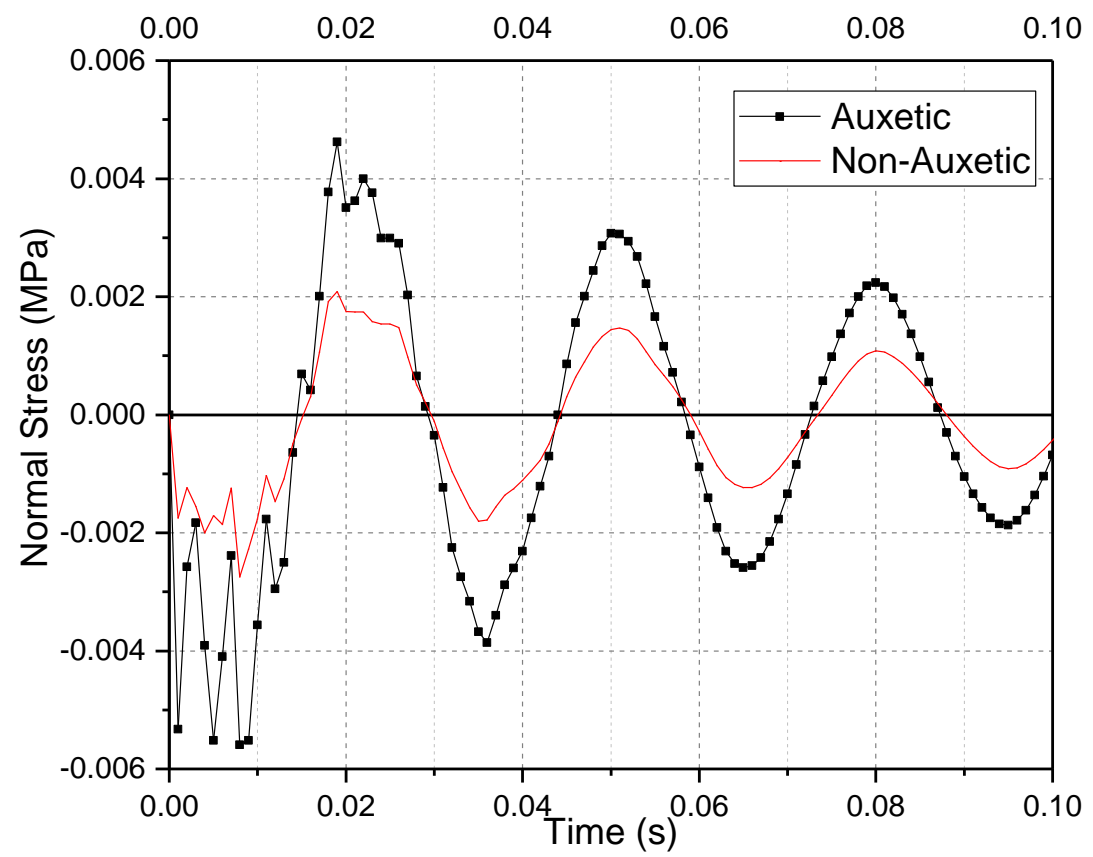

(b)

Fig. 16 (a) Shear stress time histories in MPa, (b) Normal stress time histories in MPa. 
during the study, no any other data were used to support this study.

\section{Conflicts of Interest}

The author declares that there is no conflict of interest regarding the publication of this paper.

\section{Acknowledgement and Funding}

Not applicable.

\section{References}

[1] Lakes, R. S. 1987. "Foam Structures with a Negative Poisson's Ratio.” Science 235 (4792): 1038-40.

[2] Mir, M., Ali, M. N., Sami, J., and Ansari, U. 2014. "Review of Mechanics and Applications of Auxetic Structures." Adv. Mater. Sci. Eng. 1-18.

[3] Lim, T.-C. 2015. Auxetic Materials and Structures.

[4] Yang, W., Li, Z., Shi, W., Xie, B., and Yang, M. 2004. "Review on Auxetic Materials." J. Mater. Sci. 39: 3269-79.

[5] Prawoto, Y. 2012. "Seeing Auxetic Materials from the Mechanics Point of View: A Structural Review on the Negative Poisson's Ratio." Comput. Mater. Sci. 58: 140-53.

[6] Evans, K. E., and Alderson, A. 2000. "Auxetic Materials: Functional Materials and Structures from Lateral Thinking!" Adv. Mater. 12 (9): 617-28.

[7] Evans, K. E., and Alderson, K. L. 2000. "Auxetic Materials: The Positive Side of Being Negative." Eng. Sci. Educ. 149.

[8] Liu, Y., and Hu, H. 2010. "A Review on Auxetic Structures and Polymeric Materials.” Sci. Res. Essays. 5 (10): 1052-63.

[9] Smith, C. W., Grima, J. N., and Evans, K. E. 2000. "Novel Mechanism for Generating Auxetic Behaviour in Reticulated Foams: Missing Rib Foam Model." Acta Mater. 48 (17): 4349-56.

[10] Gaspar, N., Smith, C. W., Alderson, A., Grima, J. N., and Evans, K. E. 2011. "A Generalised Three-Dimensional Tethered-Nodule Model for Auxetic Materials.” J. Mater. Sci. 46 (2): 372-84.

[11] Cabras, L., and Brun, M. 2014. "Effective Properties of a New Auxetic Triangular Lattice: An Analytical Approach.” Fract. Struct. Integr. 8 (29): 9-18.

[12] Cabras, L., and Brun, M. 2014. "Auxetic Two-Dimensional Lattices with Poisson's Ratio Arbitrarily Close to -1.” Proc. R. Soc. A Math. Phys. Eng. Sci. 470 (2172).

[13] Choi, J. B., and Lakes, R. S. 1991. "Design of a Fastener
Based on Negative Poisson's Ratio Foam." Cell. Polym. 10 (3): 205-12.

[14] Bettini, P., Airoldi, A., Sala, G., Di Landro, L., Ruzzene, M., and Spadoni, A. 2010. "Composite Chiral Structures for Morphing Airfoils: Numerical Analyses and Development of a Manufacturing Process." Compos. Part B Eng. 41 (2): 133-47.

[15] Yang, L., Harrysson, O., West, H., and Cormier, D. 2013. "A Comparison of Bending Properties for Cellular Core Sandwich Panels.” Mater. Sci. Appl. 8: 471-7.

[16] Scarpa, F., Giacomin, J. A., Bezazi, A., and Bullough, W. A. 2006. "Dynamic Behavior and Damping Capacity of Auxetic Foam Pads." p. 61690T.

[17] Caddock, B. D., and Evans, K. E. 1989. "Microporous Materials with Negative Poisson's Ratios. I. Microstructure and Mechanical Properties." Journal of Physics D: Applied Physics. Available: http://stacks.iop.org/0022-3727/22/i=12/a=012?key=cross ref.bb1ba52ef017a0a8850ae1a00b9c81c7.

[18] Alderson, K. L., Alderson, A., Smart, G., Simkins, V. R., and Davies, P. J. 2002. "Auxetic Polypropylene Fibres: Part 1 Manufacture and Characterisation." Plast. Rubber Compos. 31 (8): 344-9.

[19] Ravirala, N., Alderson, A., Alderson, K. L., and Davies, P. J. 2005. "Expanding the Range of Auxetic Polymeric Products Using a Novel Melt-Spinning Route.” Phys. Status Solidi Basic Res. 242 (3): 653-64.

[20] Janus-Michalska, M. 2009. "Micromechanical Model of Auxetic Cellular Materials.” J. Theor. Appl. Mech. 47 (4): 737-50.

[21] Alderson, A., and Alderson, K. L. 2007. "Auxetic Materials." Proc. Inst. Mech. Eng. Part G J. Aerosp. Eng. 221 (4): 565-75.

[22] Scarpa, F. 2008. "Auxetic Materials for Bioprostheses." IEEE Signal Process. Mag. 25 (5).

[23] Martz, E. O., Lakes, R. S., Goel, V. K., and Park, J. B. 2005. "Design of an Artificial İntervertebral Disc Exhibiting a Negative Poisson's Ratio." Cell. Polym. 24 (3).

[24] Smith, F. C., Scarpa, F., and Chambers, B. 2000. "The Electromagnetic Properties of Re-Entrant Dielectric Honeycombs." IEEE Microw. Guid. Wave Lett. 10 (11): 451-3.

[25] Chen, C. P., and Lakes, R. S. 1996. "Micromechanical Analysis of Dynamic Behavior of Conventional and Negative Poisson's Ratio Foams." J. Eng. Mater. Technol. 118 (3): $285-8$.

[26] Scarpa, F., Ciffo, L. G., and Yates, J. R. 2004. "Dynamic Properties of High Structural İntegrity Auxetic Open Cell Foam." Smart Mater. Struct. 13 (1): 49-56.

[27] Shen, Y., Golnaraghi, F., and Plumtree, A. 2001. "Modelling Compressive Cyclic Stress-Strain Behaviour 
of Structural Foam." Int. J. Fatigue 23 (6): 491-7.

[28] Darja, R., Tatjana, R., and Alenka, P. Č. 2013. "Auxetic Textiles." Acta Chimica Slovenica 60 (4): 715-23.

[29] Yang, L., Harrysson, O., Cormier, D., West, H., Park, C., and Peters, K. 2013. "Design of Auxetic Sandwich Panels for Structural Applications." Solid Free. Fabr. Proc. 929-38.

[30] Miller, W., Hook, P. B., Smith, C. W., Wang, X., and E. Evans, K. 2009. "The Manufacture and Characterisation of a Novel, Low Modulus, Negative Poisson's Ratio Composite." Compos. Sci. Technol. 69 (5): 651-5.

[31] Mohanraj, H., et al. 2016. "Hybrid Auxetic Foam and Perforated Plate Composites for Human Body Support." Phys. Status Solidi Basic Res. 253 (7): 1378-86.

[32] Bhullar, S. K., Ko, J., Ahmed, F., and Jun, M. 2014. "Design and Fabrication of Stent with Negative Poisson's Ratio.” Int. J. Mech. Ind. Sci. Eng. 8 (2): 1-7.

[33] Sanami, M., Ravirala, N., Alderson, K., and Alderson, A.
2014. "Auxetic Materials for Sports Applications." Procedia Engineering 72: 453-8.

[34] Tatlier, M., and Berhan, L. 2009. "Modelling the Negative Poisson's Ratio of Compressed Fused Fibre Networks." Phys. Status Solidi Basic Res. 246 (9): 2018-24.

[35] Tatlier, M. S., and Aksu, U. 2017. "Simulation of Auxetic Behavior in Planar Random Steel Fiber Networks." Int. J. Appl. Eng. Res. 12 (13): 3978-87.

[36] Scarpa, F., Panayiotou, P., and Tomlinson, G. 2000. "Numerical and Experimental Uniaxial Loading on İn-Plane Auxetic Honeycombs." J. Strain Anal. Eng. Des. 35 (5): 383-8.

[37] Korner, C., and Liebold-Ribeiro, Y. 2015. "A Systematic Approach to İdentify Cellular Auxetic Materials.” Smart Mater. Struct. 24 (2).

[38] CSI. 2016. "CSI Analysis Reference Manual.” Berkeley (CA, USA) Comput. Struct. INC, p. 534. 